Wilfrid Laurier University

Scholars Commons @ Laurier

Lyle S. Hallman Social Work Faculty

Publications

Lyle S. Hallman Faculty of Social Work

$3-17-2016$

\title{
Practice-based Qualitative Research: Participant Experiences of Walk-in Counselling and Traditional Counselling
}

\author{
Cheryl-Anne Cait \\ Wilfrid Laurier University, ccait@wlu.ca \\ Michelle J. Skop \\ Wilfrid Laurier University, skop1770@mylaurier.ca \\ Jocelyn Booton \\ Wilfrid Laurier University \\ Carol Stalker \\ Wilfrid Laurier University, cstalker@wlu.ca \\ Susan Horton \\ University of Waterloo
}

See next page for additional authors

Follow this and additional works at: https://scholars.wlu.ca/scwk_faculty

Part of the Social Work Commons

\section{Recommended Citation}

Cait, Cheryl-Anne; Skop, Michelle J.; Booton, Jocelyn; Stalker, Carol; Horton, Susan; and Riemer, Manuel, "Practice-based Qualitative Research: Participant Experiences of Walk-in Counselling and Traditional Counselling" (2016). Lyle S. Hallman Social Work Faculty Publications. 17.

https://scholars.wlu.ca/scwk_faculty/17

This Article is brought to you for free and open access by the Lyle S. Hallman Faculty of Social Work at Scholars Commons @ Laurier. It has been accepted for inclusion in Lyle S. Hallman Social Work Faculty Publications by an authorized administrator of Scholars Commons @ Laurier. For more information, please contact scholarscommons@wlu.ca. 


\section{Authors}

Cheryl-Anne Cait, Michelle J. Skop, Jocelyn Booton, Carol Stalker, Susan Horton, and Manuel Riemer 
Practice Based Qualitative Research: Participant experiences of Walk-In Counselling and Traditional Counselling

\begin{abstract}
Walk-in single session counselling is becoming a more widely used model for delivering mental health services across Ontario. This paper reports findings from the qualitative phase of a mixed method study, exploring the experiences of those attending walk-in counselling (WIC) model compared to the traditional service delivery model employing a wait list. We used a comparative case study design for the qualitative phase. Findings reveal that participant outcomes of the walk-in counselling model is influenced by accessibility, how a participant makes sense of the service, and the degree to which a participant is motivated and able to engage in counselling. WIC supports the mental health system by reducing wait lists associated with traditional service delivery models, and meeting the needs many people identify for immediate consultation. Other participants still perceive themselves as requiring ongoing counselling over time and involving in-depth exploration. This research supports health systems providing access to both models.
\end{abstract}

\title{
Keywords
}

Walk-in counselling, single session therapy, service delivery models, mixed methods, case study 


\section{Introduction}

Over the past decade in Ontario, community-based mental health agencies have increasingly turned to the walk-in counselling (WIC) model of service delivery to reduce wait times and improve accessibility for service users. The purpose of our overall research was to compare outcomes for clients of two family service agencies serving similar client populations in two separate cities using two different models of service delivery. The models include a WIC service delivery model offering single session counselling and the traditional service delivery model whereby clients telephone to request service, and after talking with an intake worker, are usually placed on a wait list.

Quantitative findings from phase 1 of our study that used multi-level modelling revealed clients of the walk-in model improved faster and were significantly less distressed as assessed by the General Health Questionnaire-12 (GHQ-12) at the four-week follow-up compared to the clients of the traditional service delivery model. At the ten-week follow-up, both groups were less distressed compared to baseline, and mean GHQ-12 scores for the two groups were similar. ${ }^{1}$ (Stalker, Reimer, Cait, et al., 2015). A moderator analysis suggests that, on average, clients with mood issues (i.e., anxiety and depression) profit more from the walk-in model compared to those with other issues, at least during the weeks immediately following the single session. Contrary to our expectations, clients presenting with issues we termed 'complex needs' ${ }^{2}$ who received service from the walk-in model also improved more quickly than clients presenting with

\footnotetext{
${ }^{1}$ At the four-week follow-up, $23.5 \%$ of participants requesting service from the traditional model had seen a counsellor at least once in the previous four weeks. At the 10-week follow-up, $24.8 \%$ had seen a counsellor at least once in the previous four weeks.

2 These include participants who at baseline reported they were coping with abuse, or indicated they had a child welfare issue, trauma/PTSD, serious mental illness or harm to self. These issues have been reasons for exclusion from previous studies of single session therapy or walk-in counseling.
} 
complex needs at the agency employing the traditional model. The difference between the clients of the two delivery models in the rate of change over time for those without complex needs was less pronounced (Reimer, Stalker, Dittmer, et al., manuscript in progress).

Our research team also integrated a qualitative case study component into the mixed methods study to provide a more comprehensive account of both models of service delivery. The qualitative component sought to understand past counselling experiences of participants, the nature of their personal difficulties and the significance of these for current service use and their assessment of the model of service used. Qualitative health outcome research 'strives to inspect the relationships between personal difficulties, experiences, policies, interventions and institutions' (Shaw, 2003, p.68). Qualitative health research highlights details of a situation or interaction holding significance for practice and practitioners (Morse, 2012). This paper focuses on the qualitative findings of the research.

\section{Situatedness and guiding theory}

As social workers, our interest in this research lies in our training and history of providing clinical mental health services, which has been based in theoretical approaches, such as contemporary psychoanalytic, more synonymous with longer-term service provision. In contrast, through the research, we sought to understand the experiences of participants using either WIC or a traditional model of service delivery. A pre-judgment of ours might be that longer-term counselling is more effective in service provision than a single session. Throughout the research process we created a reflexive space for dialogue, questioning our own assumptions and self-understanding about the process of service delivery. 


\section{Background}

\section{Re-thinking service provision}

Single session counselling is defined as 'a planned single-session intervention - not to the situation where a client is offered more sessions but chooses to attend just one' (Hymmen, Stalker, Cait, 2013, p. 61). Walk-in and single session counselling can be different: not all single session counselling is walk-in and not all walk-in is single session. Many WIC clinics (WICC) do permit another meeting, although it might be with a new counsellor. Despite these differences, both draw on research evidence and share many foundational philosophical principles. Research suggests that across modes of service provision a majority of service users attend counselling for one or two sessions (O’Neill and Rottem, 2012; Perkins and Scarlett, 2008; Talmon, 1990). The majority of service users receiving a single session, either scheduled or through walk-in, find it sufficient, satisfactory and helpful (Harper-Jaques and Foucault, 2014; Harper-Jaques, McElheran, Slive and Leahey 2008; Hymmen, Stalker, Cait, 2013). Research indicates people make more improvement in the earlier stages of counselling with decreasing improvement as number of sessions increase (Baldwin, Berkeljon, Atkins, et al., 2009; Bloom, 2001; Harnett, O’Donovan, and Lambert, 2010). The aim of the walk-in model is to provide a 'whole therapy' in one session knowing people may not return (Campbell, 2012; Harper-Jaques and Foucault, 2014).

Single-session and walk-in counselling services are often provided by social workers, among other mental health practitioners, and tend to utilize approaches based on post-modern, constructionist, narrative and systemic theories; however, no one approach is seen as superior to another. For walk-in, a pragmatic perspective is most important, that is, practice approaches that are most useful and the best fit for a client at any given time. Foundational principles include: 
people identify when they need help and what suits them best; elicit and highlight client strengths; it is best to engage someone when ready for counselling rather than when service is permitted by wait-lists; service users can benefit from a single session without requiring more; referral to other services are helpful and often required (Talmon and Hoyt, 2014; Slive and Bobele, 2012; Slive, McElheran and Lawson, 2008). The principles of single-session WIC reflect social work values, as the focus is on reducing systemic barriers, improving access to resources, and respecting clients' right to self-determination.

\section{Underpinnings of single session walk-in counselling}

Single session counselling can be considered as a therapeutic consultation (Winnicott, 1971). The counsellor provides a space where hopes and expectations of helpfulness are held, creating a secure base from which people can move forward toward goals after the encounter (Jerry, 1994, Winnicott, 1971). As a consultation process, the counsellor offers ideas, many of which are inspired by the service user; the service user decides whether to accept and/or use these ideas and chooses next steps. The counsellor's role is to act as a guide and not 'to take responsibility for client change' (Slive, McElheran and Lawson, 2008, p.11). The service is meant to provide 'emotional relief' (Slive, McElheran and Lawson, 2008, p.12), options for problem-solving, and create a feeling of hope and sense of self-efficacy (Cameron, 2007; Feldman and Dreher, 2012; Harper-Jaques and Foucault, 2014; Slive, McElheran and Lawson, 2008; Young, Dick, Herring et al., 2008). The single session is about having a conversation in 'ways that step away from the usual conversations they have been having about the situation and create an unusual enough conversation that can bring forward new possibilities' (Young et al., 2008, p. 28). By increasing the accessibility of counselling, the counsellor capitalizes on the service user's motivation. 


\section{Methodology and methods}

We used a sequential explanatory design (Ivankova, Creswell, and Stick, 2006) involving the collection of quantitative data and analysis in the first phase, with qualitative data collection and analysis following in phase two of the research. A comparative case study design guided the qualitative phase (Yin, 2014). Case studies are used to help understand the 'how' and 'why' about a particular case (Yin, 2014, 2009). The indicator of client outcome in the first phase of the study was identified through improvement on the GHQ. In the second phase of the study we wanted to understand qualitatively how participants constructed their experiences with the two different models of service delivery; that is, to examine the relationships between people's past experiences, current difficulties and experience of the different models of service delivery. We interviewed participants from two agencies to help elucidate the specificities of the walk-in counselling model and to identify areas of similarity and difference between the walk-in and traditional counselling models. Recruitment and collection of quantitative and qualitative data (except for recruitment and baseline at the walk-in clinic) was completed over the phone due to the disparate locations of a high number of participants.

We selected agencies/cases in part directed by preliminary research (Stalker, Horton, Cait, 2012) with Agency A, which offers WIC. Agency B was selected as the comparison group because it serves a similar population to Agency A and did not have a WICC. Both agencies are in urban areas located within a one and a half hour drive from each other. We began our research after receiving approval from the Wilfrid Laurier University Research Ethics Board. 


\section{Participant selection for qualitative case study}

To be selected for a telephone interview, participants completed quantitative data collection at all three points and agreed to be contacted for a phone interview. Preliminary quantitative analysis indicated participants from both sites improved overtime as measured by the General Health Questionnaire-12 (GHQ-12). From these findings, we created three different selection categories based on GHQ-12 scores: participants who improved (trend), participants who did not change (non-trend), and participants who deteriorated (non-trend). Some prior studies of single session counselling excluded clients presenting with more severe mental health issues, including issues around trauma because it was believed this approach might not be helpful for this group (Cameron, 2007). From discussions with the agency we were aware that people dealing with trauma did utilize WIC and from initial quantitative analysis we did see improvement based on the GHQ-12 scores. Because previous research had not included this group we were particularly interested in understanding why these participants found WIC helpful and took this into consideration in case selection. We conducted 48 telephone audio-recorded interviews. Participants who had completed surveys at all three time points were asked for permission to be contacted at a future point in time to discuss the qualitative study. If they agreed, participants were sent the information letter about the study. When we determined what participants we were interested in interviewing, those people were contacted, after the 10-week quantitative follow-up and asked if they would be willing to be interviewed. Consent forms were reviewed while on the phone and those who agreed to participate proceeded with the interview. The consent form, along with a \$10 gift card was then mailed to participants following the interview. We terminated sampling based on both the belief that the interviews were not providing any new 
information (saturation) and that the interviews provided us with multiple perspectives

(Charmaz, 2014).

\section{Data collection}

We developed an original semi-structured interview guide for the qualitative telephone interviews, which lasted 20 to 30 minutes. This guide included open-ended questions and planned prompts to meet the needs for both structure and consistency in the interview (Rabionet, 2011). The interview guide was revised based on emergent themes from initial interviews. We gathered comprehensive information through the interview guide about the participants at each agency, including: presenting problem, nature of psychological distress, their experiences with the service delivery model and the counsellor with whom they met, how each has or has not been helpful, other services used (or not) and reasons for alternative service use. The interviews were conducted by a doctoral candidate and the research coordinator between January 2013 and March 2014.

\section{Data analysis}

We reviewed transcriptions of the telephone interviews for accuracy before analysis began. A case study approach with more than one case involves analysis both within each case (model) and across cases (models) (Yin, 2014). We started the qualitative analysis inductively, allowing us to hear the words of participants without being constrained by quantitative findings. We conducted a thematic analysis involving organization of data into patterns/themes, followed by a cross-case thematic analysis. Coding involved five phases: becoming familiar with the data, creating initial codes, assembling codes into themes, naming and defining themes, and finally, integrating qualitative findings with quantitative findings to answer the research questions (Guest, MacQueen, and Namey, 2012). Memos were written for each interview summarizing the 
service process and detailing the overall impression of the interview. Initial coding was done using N-VIVO data analysis software. Preliminary analysis produced close to 80 initial codes. We had lengthy discussions around these codes helping to refine our thinking and to reach consensus on final codes and their definitions. We constructed our main themes by reviewing our memos and conceptualizing the codes on a broader level. We found the common themes transcended both cases. Trustworthiness, credibility and verification of data were established through intercoder agreement (three coders), lengthy and rigorous discussions identifying areas of difference to reach clarity on codes, memo-taking and further sampling (interviewing) (Houghton, Casey, Shaw, and Murphy, 2013; Houghton, Murphy, Shaw, and Casey, 2015). The cases

In 2007, Agency A launched a WIC service in response to a waiting list of 981 service users. The WIC model at Agency A consists of a brief intake/assessment followed by a one to 1.5 hour session. The walk-in serves individuals of all ages, couples and families. The WICC at Agency A is open one day per week from noon until 6:00 p.m. The counsellor commonly uses an approach that focuses on people's strengths and draws from a variety of theoretical orientations including but not limited to narrative, systemic and cognitive behavioural. In cooperation with the service user, a written plan is developed. At family service Agency B, with no WICC, the agency provides three to five telephone intake appointments per day, receiving approximately eight to fifteen calls for service per day. People calling after the daily quota of intake appointments is reached are asked to call back the next business day. Individuals calling early enough to be included in the daily quota are given a telephone appointment with an intake worker, usually within a few days. Following the telephone intake interview, the intake worker 
normally places the caller on a wait list. The intake worker also informs callers about other community services that may be helpful to them.

\section{Phase Two Findings}

\section{Demographic information}

The mean age of the 48 participants in the qualitative phase was 34 years, with a range of 16-59 years. Thirty-four identified as female; 14 identified as male. Thirty-two had a household income of CA $\$ 19,000$ or less; eight had an income between CA $\$ 20,000$ and CA $\$ 39,999$; seven had an income of CA $\$ 40,000$ or above. Thirteen reported a relationship status of married/common-law; 22 reported being single; seven were separated or divorced; five reported being in some kind of couple relationship. Forty-three identified English as their primary language; one French; four other. Employment status was described as the following (more than one answer could be chosen): six were full-time, eight were part-time, three were self-employed, nine were in school, 11 were unemployed, 16 were on social assistance or provincial disability pension, two were homemakers, one was retired. Of note are the structural influences and implications of the sample. More than half of the people interviewed had a household income of CA $\$ 19,000$ or less. From this we concluded the people in this study did not have the financial resources to obtain mental health services privately, thus limiting their options for counselling.

\section{Participant Experiences}

Participants discussed their experiences with WIC and traditional counselling service models within the larger web of their lives. They had space to provide a history of their help seeking, their personal histories and life experiences. We created the overarching category Participant Construction of Life Circumstances to capture the complexity of people's lives and to be able to root information about services within this larger context. We defined this category as: the 
participant's description and understanding of his/her personal history and experiences. Having this level of detail allows us to review the relationships between people's past and present experiences including personal struggles, different interventions and agency policies. The themes, in interconnected ways, help explain the participant's experience with each service provision model: accessibility, meaning of service and readiness for service.

\section{Accessibility}

The most salient theme for participants in terms of service experience was accessibility. We defined this as: the barriers and/or facilitators, which influence a person's ability to obtain and receive services. Participants valued the accessibility of the walk-in model; however, that in and of itself was not enough to render the service helpful. It would be simplistic and incomplete to suggest that the walk-in model was useful only because of its accessibility and likewise all those who had to wait for service did not receive valuable help. In presenting the findings we are mindful of the complexity of participant/s' experiences.

One participant attending walk-in explained looking for some help around his relationship with a former girlfriend: 'I was just looking at options for um, what we could do to kind of help the situation and get an outside opinion.' He discusses why accessibility of the walk-in session was important for him and how he found it helpful:

Um it was nice when you have these things on your mind you kind of want to get if off right away ... So it was nice to have somebody there that day to you know, vent a little bit ...Uh just to I guess talk and uh, you know, see if I can get some answers out of myself almost just from kind of saying everything out loud instead of in my head ... When you talk to um, friends or family or that stuff, they're going to be biased based on their outside view of things, but when you come into the counselling session it's a total 
outside perspective on everything. They're not judging anything based on past knowing of anything of me or my ex or anything, it was just listening to everything I had to say about it.

In discussing the counsellor he said she was: very comforting in the way that she would ask questions and yeah it didn't come across as invasive or uncomfortable like. Yeah like almost like I'd known her for a long time. Or she knew my history or something like that.

This participant was able to 'vent' about his experience, and through articulating his thoughts out loud he came to his own answers. The timeliness of the service and this participant's ability to take advantage of the nature of the service was helpful. Added dimensions increasing the usefulness of walk-in included: being able to get an 'outside perspective', hence the anonymity of the session; the counsellor's being a good listener, and being able to ask non- invasive questions. Feeling a strong connection with the counsellor was also significant.

Another participant reported having used walk-in service previously for, 'anything and everything really. Anything that was troubling me that I didn't feel I had the coping skills or know-how to push through an issue.' For her the process of getting into walk-in was, 'easybreezy' and 'really reasonable.' When she had called for counselling at other agencies and even including the agency where walk-in is held she was told there was a two to three month waiting list. She further clarifies why accessibility is so important:

It's optimal because I would say that if I couldn't have gotten in when I needed help that I would have been overwhelmed and probably been at the point of self-harm ...Pretty much any time that I've ever gone and I've gone in because I just don't have the coping skills to get through a situation. 
We also find out how she found the session helpful:

I definitely need empathy um, I just need someone to give me real good direction so that I can get the skills to be able to cope without being able to return over and over again ... I come out feeling um, so relieved and that I truly have enough skill to, um, be able to cope with the situation and if it was to arise again the know-how of what to do and basically to get validation that you don't just feel like, um, you are alone with this situation ... I'm quite visual, so, um, it was helpful to draw some things out on paper. Writing them down to give me a set of know-hows and to-dos, to kind of go home and work on and she recommended a couple of books too which I got and read ... You don't just walk away you do have a game plan.

This participant speaks to the critical nature of timely and accessible service when she says she would have been at the point of self-harm if she were not able to speak to someone. She was able to regain a sense of control over her life after having a directive session focused on skills acquisition and a written plan with which to move forward. Also important for this participant, is not having to return 'over and over again.'

Participant voices from the comparison agency without a walk-in also accentuate accessibility. Some participants had not seen anyone at Agency B even by the time we interviewed them; others turned to different services for help and still others were able to wait and found the service very helpful. The following woman had been to Agency B previously. She finds waiting difficult but knowing what to expect helps her 'mentally prepare' so she can get through the wait period:

It was frustrating and it was uh, quite a long wait period for sure. Yeah it was twelve weeks I think. Um it was hard. I guess the way I got through was that I knew before I 
called that there was going to be a wait period. I didn't know that the first time I went into it. I guess I had to mentally prepare ahead of time to just try to tough it out until I could get in there. And if I was maybe an individual that didn't have an amazing family and group of friends to support me then it would have been a much harder struggle and I think other people might - could get into a dangerous position in their lives, very vulnerable without support for that amount of time ...

She continues to discuss her experience of the traditional model:

Like I know that I can't heal everything um, so I still struggle sometimes but um, the counsellor was awesome and I definitely feel like she gave me some tools to use to be able to cope and to start rebuilding my life and rediscovering myself ... She sort of - she did a lot of listening and then sort of just helped me rethink my own thoughts and my own perspectives by almost mirroring them back to me. She was good. She kind of made me do some of the work too but I needed that, so...

This person echoes many of the same experiences the two earlier participants discuss in how and why counselling can be useful: space to think through one's thoughts out loud, feeling listened to, developing coping tools for the future and for understanding self. The last narrative differs in discussing accessibility. This woman needs to 'mentally prepare' for a wait. We are left asking what if she didn't know what to expect and if she couldn't mentally prepare for the wait period? Accessibility not the only story

Learning about people's personal histories particularly their previous experience with counselling provides further context for understanding why or why not someone finds accessibility central to their service experience. The next two examples suggest some people chose walk-in because of the level of accessibility it offers, are familiar with counselling but 
were ultimately hoping and looking for ongoing counselling. One woman shared, 'I really wanted to do the talk therapy cause I have had positive results with that before.' She decided to go to Agency A specifically because they had a walk-in clinic and she did not want to wait for service. In the walk-in session she spent some time brainstorming with the counsellor about how she could help herself. She wishes the session would have been more helpful than it was, 'I would like to say it was much more useful. It wasn't as useful as I thought it was going to be. Um, some of the stuff I had already been doing and I needed, I think I needed more of a session where you sit down and really talk to somebody, instead of just a brainstorm.'

Similarly another participant explains she has had counselling before and was looking for a place with ongoing service. She describes walk-in as:

very welcoming and um, willing to help I would say, but I guess, I just came out from there not being clear of what I needed to do after because um, my understanding was that the walk-in clinic wouldn't see you on an ongoing basis ...it was welcoming, it was warm the counselling - counsellor but um, like I felt comfortable, it was just a little quick it was nice to chat with them, it was just short ... And not as clear as I wanted to be. Previous experiences with counselling can influence expectations of the walk-in model. Some who have not had as positive an experience with counselling might be looking only for a single session while others as cited above are hoping for ongoing counselling and do not find the one session is long enough to delve into all their issues or talk as in depth about one issue as they would like. For some people, having a directive session and being able to brainstorm is helpful and for others being able to discuss all of one's issues, 'really talk to someone' over a longer period of time is more useful. Having an accessible service when a participant is motivated and ready to do something different is important; however, it is not enough to make the service 
experience meaningful for everyone. Some people are hoping for something more than the walk-in can offer - and that is time. A layered perspective on participant experiences of walk-in provides a multidimensional and complex story.

\section{Meaning of service}

We noted earlier that the themes were interconnected. The theme of accessibility links to the theme of meaning of service defined as: a participant's way of making sense of their experience. In the next two examples we can further see the relationships between a participant's problems, past experiences and perception of current interventions. Meaning of service helps advance understanding about why a service is deemed helpful or not. One participant describes how, when she was very young, she battled depression after her mother got sick. She had a history of seeking help but, referring to the services and counsellors she said, 'They didn't really work well with me ... So I just stopped seeing them or they fired me eventually.' In the interview, this woman describes ongoing issues throughout her life for which she has sought support and counselling: 'I have a lot of issues. I don't know if anyone can really, you know say that perfect thing that is going to make them go away.' At the time of the interview she said: 'I was really depressed and alone and I was starting to feel like my old patterns of depression were coming back and that is never a good thing, so I wanted to nip it in the bud.' This woman saw a flyer at her doctor's office for walk-in counselling and because she describes herself as proactive about her health and at the point of needing to do something, walk-in was a good option. She wanted some helpful tips to help her break some depleting patterns. The ease with which she was able to receive service, accessibility, was very important for this woman as she describes, 'getting myself to do anything is a struggle most days whether it's fatigue from multiple sclerosis or pain 
from whatever or just feeling anxiety and just depression and worthlessness.' Later in the interview she says:

Just going out of the house that day I felt really good ... So I'm like okay I'm going to do this and I was scared as shit leaving but I felt good about it for just that. Getting that done ... no, I felt a lot better after I left. I felt like she was very helpful and gave me encouragement to do things and that is kind of hard for me. So, to say that she helped me with that, that was pretty cool.

Walk-in is significant for this woman, not only because of the accessibility but the structure of the service. It was accessible and it was not ongoing. She discusses past counselling as not helpful, so having a single session model of service delivery likely increased her motivation to go to the WICC.

This participant also explains how getting out of the house is extremely important and very difficult because of her struggles with anxiety. She wanted to prove to herself and her husband she could motivate herself. Her immediate goal, getting out of the house, was facilitated by knowledge of the walk-in service available that day; however, there was still the obstacle of having to travel by bus quite a distance to get to the agency. She was able to overcome this. We imagine knowing this was not a place she would be returning on a weekly basis was helpful for that. One of the pieces this woman worked on in counselling was developing options for things to do that help her get out of the house and feel less depressed. Her narrative suggests the sense of self-efficacy and agency she feels just getting to the WICC put her in a positive mindset to benefit from feedback from the counsellor and to trust the resources she already possesses. In this situation, accessibility was as therapeutic and valuable as the clinical encounter or intervention. The role of expert is redefined. How this participant 
makes sense of her experience provides an alternative discourse regarding what is considered helpful. Helpfulness, in this case, includes the immediacy of being able to speak with someone, having a single complete session, receiving helpful tips without having to provide an entire history. Helpfulness occurs before and beyond the clinical encounter. In this situation the participant experiences the power to define the problem, the solution and the timing of the intervention.

Another participant has had ongoing difficulties since she was a teenager and has also received previous counselling. When attending counselling as a teenager she felt she was the 'problem', being told she was one thing or another, 'I just felt like I didn't want to go back to counselling because I felt like you know maybe they were right.' This woman sensed that counselling contributed to her feeling of being 'sick' and prevents her from attending counselling or going to walk-in earlier:

Yeah it is one of those things that I feel like, you know, I've been going to a psychologist since I was young. And when I was in high school and you know, sometimes I feel like by going to those places that I'm um, I'm sick and I don't like that. I don't like the way I was treated you know because they would always come up with these little things about, all they told me was that I need medication you need this, you need that . . . And sometimes I felt like they were trying to put stuff in my head that I would, eventually was starting to go, oh well, “I'm a sick person". That's not how I feel like, like right now I feel like uh I've been able to cope with myself better without, you know, having those people say things in my head. So, I think in a way for me it was just trying um, not to go through with all of that again. 
The accessibility of meeting with a counsellor without having to first call for an appointment was a key factor in her decision to attend the walk-in. The meaning of walk-in for her stood in contrast to how she recognized previous counselling. It was an opportunity to meet with someone once and to 'vent' her emotions differently than she could with family or friends. She tells us at walk-in, the counsellor was 'actually giving me feedback instead of just listening.' The session was directive and practical. This participant was interested in a space for emotional release. She experienced the single session as 'de-pathologizing and de-stigmatizing' in contrast to her previous experience.

The meaning of service was also a theme in examples from participants attending Agency B, the traditional model. Another participant we interviewed had been to Agency B previously and having had a very positive experience describes calling the service and knowing she was returning to counselling as a huge relief and feeling very comforted:

I think that's part of the reason my anxiety was relieved was that I knew that I was going to speak to her. I knew I was going to be very comfortable with her. I knew we could probably carry on from where we left off in a way ... I just have had a fantastic rapport with her um, she's very sincere, she remembered. I've been really surprised at how well she remembers things I must have told her a couple of years ago ...Like she'll you know, say something like well in your family, you know such and such and it's like, wow, I hadn't thought of that but you are right and um, you know it just has surprised me. So she's very attentive, very sincere I feel like she's right with me in the sessions. I never get a sense that she's distracted or thinking about something else ...just as you're talking, she listens, she nods her head she is very intently listening and she gives very um, real feedback. 
Even though there was a wait for service, mitigating this, the participant was able to access a familiar service and see the same counsellor. Her commentary above is entirely focused on the counsellor with whom she felt very attached. Counsellor characteristics that are helpful from Agency A are again equally important in Agency B, sincerity, a good listener and being attentive. Agency B in contrast to Agency A provides a sense of continuity for this woman because she is able to return to the same counsellor. The consistent presence of the counsellor over a period of time (even though there had been a break in service) was very meaningful and helpful for this participant. In contrast to this, walk-in by its structure cannot normally provide this continuity and perhaps the level of attunement this woman experiences. The meaning of consistency provided through counselling at Agency B is very important for this participant.

\section{Readiness for service}

Readiness for service, another theme in our qualitative analysis is defined as: the degree to which the participant feels motivated and able to commit to engage in counselling. This is linked to self-agency in being motivated, ready and open to accessing and receiving counselling, which can mean something very different for WICC as opposed to the traditional model using a wait list. One participant, from Agency A, voices that, after five years of being sober, she had started to drink again and this was increasing along with her depression. Her boyfriend had just gone to jail and she was having difficulty leaving her apartment. She explains her 'depression and anxiety and PTSD has always been there.' This participant speaks about not really wanting help but still accessing walk-in: 'I wasn't in a period, like I just hated the world and I just really didn't want help I just wanted to sit in my own self-pity.' She further clarifies what was helpful about the walk-in session: 'Just talking to somebody for even that little bit of time . . . having her write down things and tell me things. She was very positive with me and that I know a lot, because I 
do know a lot.' The walk-in single session service for this woman 'who really didn't want help' seems to have been both motivating in terms of accessing service and also engaging in terms of its helpfulness.

This woman identified her need for service, and then followed through without unnecessary rules or agency policies impairing her readiness. She was able to have someone positively reframe issues and affirm the knowledge she already possesses. This participant needed immediate assistance from a service that was easy to access. She was dealing with many complex issues requiring a pragmatic session with information written down.

Another participant, from Agency A, describes going to walk-in because she was suffering from depression and anxiety for over two years. She was a university student but decided to attend walk-in instead of the university counselling center. She described a feeling of embarrassment because she had not told anyone she was coming to the walk-in and also felt nervous, not knowing what to expect. These feelings eased for her when she entered because there were a lot of other people in the waiting room so she felt calm. She also noted the people at reception were friendly and very helpful. This made her feel more at ease. When discussing the service this participant explains:

Um, I guess that like there was help for me and ... Um that was the first time I've ever like really talked to anyone about anything ...I just felt like um it was a step in the right direction. And I just felt really comfortable with the counsellor.

When asked what made her feel comfortable, she says,

Um, she just um really compassionate ... she, she told me about like stories of like other people that have been through it and like that: "You can do it!" and she was, um, as I was 
telling her the story, you could tell that she was getting, she felt for me and like that was really nice of her.

The participant was given work sheets, numbers to call and tips to think about when she was feeling down. She explains, having never been to counselling before to deal with her depression and anxiety, it was difficult to integrate all the feedback:

Well it was my first time going and I only, I was experiencing it for like almost over a year so it was very hard to incorporate it, like, right away ... it just sort of gave me a little bit of hope but I didn't really practice anything that she gave me.

While she was not able to use all the resources, it did give her hope there were things she could do. Throughout the interview we learned this woman decided to withdraw from school temporarily, to relocate closer to home and begin to work. She also told her family about her anxiety and depression two weeks after she had been to walk-in. After re-locating she re-entered counselling, feeling that her positive experience at walk-in made requesting ongoing counselling much easier. She reports that she later re-enrolled in school.

When she left the walk-in counselling session she felt some hope and one can imagine she began to think her problem is manageable. She felt someone else was truly interested in her and her story, and was compassionate. The counsellor was encouraging and positive. After the session, although not stated, the story suggests the participant might have felt less stigmatized by her depression because she was now able to tell her family about her difficulties.

Examples from Agency B accentuate the importance of being able to access a service in a timely manner and having people determine for themselves when they are ready for service rather than having a wait list making that determination. Being motivated for and engaged in service depends on readiness and is intrinsically linked to accessibility. 
I waited quite a long time, by the time I got in to see somebody I felt like I didn't really need it anymore. So I did go to the first session, and um, it just, there wasn't anything that was particularly bothering me anymore, and um, I didn't have child care so it was going to be a lot of trouble for something I felt I didn't really need at that point.

A mother attempting to access services for her adolescent daughter from Agency B explains: Ideally I would have liked it the day she said yes ... I'm not even one hundred percent sure what changed her mind. I know she said to me that you know, I haven't had really good luck with counsellors and I think some small things probably transpired in our relationship and she just thought she didn't want to go .... I mean, she was in the mindset to go [when she made the call] and probably if we had been able to get an appointment that week, yes it probably would have made a difference because she was going to go, ... I can't remember exactly what transpired in that period of time [while on a wait list], but she changed her mind.

While the WIC model cannot be all things for all people, it can provide assistance at a time when people feel they need it the most. It can decrease disappointment with service availability. By increasing the accessibility of counseling, the counsellor takes advantage of service user motivation.

\section{Discussion}

Participant histories and experiences provide explanations for why and how clients consider a service delivery model useful. The examples discussed in this article demonstrate how qualitative data facilitates a more nuanced appreciation of research findings, thereby lending credibility to the research. 
Extracts from the interview data discussed demonstrate the importance of accessibility, meaning of service and readiness for service in terms of participants' perceptions of walk-in usefulness. There were many similarities in people's experience of helpfulness across the two service delivery models; however, participant explanation from Agency B about readiness for service and accessibility highlights themes from Agency A and the importance of both in experiencing counselling as effective. Participants can recognize when they need help. They explain how the fewer barriers to receiving services at walk-in made the experience much easier. This was the case for a participant who explained she was not ready for counselling, as well as another who found it difficult to leave her home.

Qualitative findings help corroborate the importance of many concepts infused in the design of the WIC model. In particular, we note the timely provision of service, the walk-in session as a therapeutic consultation, emotional release, the infusion of hope, the importance of feeling heard and the need to have confirmation of one's own resources and strengths (Slive and Bobele, 2012).

The narratives told by participants in this article elucidate that many people can benefit from a pragmatic consultation session (Slive and Bobele, 2012; Winnicott, 1971) with suggestions and feedback from the counsellor. The service user then works collaboratively with the counsellor to identify which option might be best. This type of session is akin to what is discussed in the literature as a 'consultation process' (Slive, McElheran and Lawson, 2008, p.11). The value of a walk-in single session also lies in its philosophy of a whole therapy in a single session. For some individuals who are not interested in returning to counselling on an ongoing basis, having a whole therapy in one session is meaningful and beneficial. 
An important part of a WICC is the creation of hope in the single session (Jaques-Harper \& Foucault, 2014; Slive, McElheran and Lawson, 2008; Young et al., 2008) and can be what makes the service meaningful for some. Snyder, Michael and Cheavens (1999) outline two components of hope, 'pathways thinking' and 'agency thinking.' The first component entails believing that ways to achieve one's goals and objectives exist. A person does not have to have actually developed the pathways to experience hope in this situation. It is just the perception that these paths are available. For one participant, the session gave the young woman a little bit of hope even though she had not actually used any of the papers provided by the counsellor. In this situation, it was enough to know that not only were there other people who had dealt with similar situations but also there were a variety of routes to address the problem. The second component of hope 'agency thinking', involves people thinking they will be able to follow and move forward with particular roadmaps, helping them obtain their goals. It is the combination of these two that Snyder (1994) has theorized leads people to meet their goals.

\section{Conclusion}

The traditional service delivery model with particular (or specific) procedures and policies about when to telephone, the intake interview, the waiting list, and then waiting for a call to schedule an appointment reinforces barriers to service. In comparison, the WIC model increases accessibility by enabling service users to bypass the wait list and the appointment scheduling process. Through walk-in counselling, service users receive counselling when they need it. It gives them more control over how and when they obtain services rather than when the governing agency allows for service. This WIC model fits with our social work values of honoring people's ability to exercise choice and transforming systems to improve access. At the same 
time, we are mindful that every service model, including the WICC, comes with its own set of rules, including time constraints that are not suitable for everyone.

This qualitative inquiry serves to provide a more complete explanation of both models of service delivery. Readily accessible single session walk-in counselling is of benefit to people when in need. It is also beneficial to the system as a whole by alleviating the pressure of waiting lists. The walk-in model can also serve to mitigate the crises and more complex consultations that ensue when difficulties fester. The traditional model provides valuable counselling to those who can wait, and many individuals and families prefer an opportunity to 'sit down and really talk' in depth and over time. This research suggests health care systems and mental health agencies need to provide access to both types of counselling in a timely way.

\section{Funding acknowledgement}

We would like to gratefully acknowledge the funding of this research by the Canadian Institutes of Health Research (CIHR), FRN 119528. 


\section{References}

Baldwin, S. A., Berkeljon, A., Atkins, D. C., Olsen, J. A., \& Nielsen, S. L. (2009) Rates of change in naturalistic psychotherapy: Contrasting dose-effect and good-enough level models of change. Journal of Consulting and Clinical Psychology 77(2): 203-211.

Bloom, B.L. (2001) Focused single-session psychotherapy: A review of the clinical and research literature. Brief Treatment and Crisis Intervention 1(1): 75-86.

Charmaz, K. (2014). Constructing grounded theory. Sage.

Guest, G. MacQueen, K. M., \& Namey, E.E. (2012). Applied Thematic Analysis. Los Angeles: Sage Publications.

Harnett, P., O'Donovan, A., \& Lambert, M. J. (2010) The dose response relationship in psychotherapy: Implications for social policy. Clinical Psychologist 14(2): 39-44.

Harper-Jaques, S. \& Foucault, D. (2014). Walk-in single-session therapy: Client satisfaction and clinical outcomes. Journal of Systemic Therapies, 33(3): 29-49.

Harper-Jaques, S., McElheran, N., Slive, A., \& Leahey, M. (2008). A comparison of two approaches to the delivery of walk-in single session mental health therapy. Journal of Systemic Therapies, 27(4): 40-53.

Houghton, C., Casey, D., Shaw, D., \& Murphy, K. (2013). Rigour in qualitative case-study research. Nurse Researcher, 20(4):12-17.

Houghton, C., Murphy, K., Shaw, D., \& Casey, D. (2015). Qualitative case study data analysis: an example from practice. Nurse Researcher, 22(5): 8-12.

Hymmen P, Stalker C.A., Cait C-A. (2013). The case for single-session therapy: Does the 
empirical evidence support the increased prevalence of this service delivery model? Journal of Mental Health, 22(1): 60-71.

Ivankova, N.V., Creswell, J.W. \& Stick, S.L. (2006) Using mixed-methods sequential explanatory design: From theory to practice. Field Methods 18(1): 3-20.

Jerry, P.A.(1994) Winnicott's therapeutic consultation and the adolescent client. Crisis intervention and time-limited treatment 1: 61-72.

Miles, M.B. \& Huberman, A. M. (1994) Qualitative data analysis. Beverly Hills, CA: Sage.

Morse, J. M. (2012). Qualitative Health Research: Creating a New Discipline. Walnut Creek: Left Coast Press.

O’Neill, I. \& Rottem, N. (2012) Reflections and learning from an agency-wide implementation of single session work in family therapy. The Australian and New Zealand Journal of Family Therapy 33(1): 70-83.

Padgett, D. (2004) The qualitative research experience. Belmont, CA: Wadsworth/Thomson Learning.

Parton, N. (1999) Reconfiguring child welfare practices: Risk, advanced liberalism, and the government of freedom. In: Chambon, A.S. Irving, A. \& Epstein, L. (eds) Reading Foucault for Social Work. New York: Columbia University Press, pp.101-130.

Perkins, R., and Scarlett, G. (2008) The effectiveness of single session therapy in child and adolescent mental health. part 2: An 18-month follow-up study. Psychology and Psychotherapy: Theory, Research and Practice 81(2): 143-156.

Price, C. (1994) Open days: Making family therapy accessible in working class suburbs. The Australian and New Zealand Journal of Family Therapy 15(4): 191-196. 
Rabionet, S. E. (2011). How I learned to design and conduct semi-structured interviews: An ongoing and continuous journey. Qualitative Report, 16(2): 563-566.

Ray, W., and Keeney, B. (1993) Resource focused therapy. London: Karnac.

Riemer M., Stalker C.A, Dittmer L., Kermani, N., Cait C-A., Horton S., Booton, J. (2015).

Single-session walk-in counselling: Who benefits the most? Manuscript in progress.

Shaw, I. (2003) Qualitative research and outcomes in health, social work and education. Qualitative Research 3(1): 57-77.

Slive, A., and Bobele, M. (2012) Walk-In counseling services: Making the most of one hour. The Australian and New Zealand Journal of Family Therapy 33(1): 27-38.

Slive, A. McElheran and N., Lawson, A. (2008) How brief does it get? Walk-in single session therapy. Journal of Systemic Therapies 27(4): 5-22.

Snyder, C.R. (1994) The psychology of Hope. New York: Free Press

Snyder, C.R., Michael, S.T., and Cheavens, J.S. (1999). Hope as a psychotherapeutic foundation of nonspecific factors, placebos, and expectancies. In: Huble, M.A., Duncan, B. and Miller, S. (eds) Heart and soul of change. Washington, D.C.:APA, pp.205-230.

Stalker C.A., Riemer, M., Cait, C-A., Horton, S., Booton, J., Josling, L., Bedggood, J. \& Zaczek M. (2015). A comparison of walk-in counselling and the wait list model for delivering counselling services. Journal of Mental Health. Published on-line: 15 December 2015. DOI:10.3109/09638237.2015.1101417.

Stalker, C.A., Horton, S. \& Cait C-A.. (2012). Single session therapy in walk-in counselling clinics: A pilot study of who attends and how they fare afterwards. Journal of Systemic Therapies. 31(1), 38-52.

Talmon, M. (1990) Single-session Therapy: Maximizing the Effect of the First (and often only) 
Therapeutic Encounter. San Francisco, CA, US: Jossey-Bass.

Talmon, M. \& Hoyt, M.F. (2014). Capturing the Moment: Single-session therapy and walk-in services. Dallas, Texas, US: Crown House Publishing.

Winnicott, D. W. (1971) Therapeutic Consultations in Child Psychiatry. New York: Basic Books

Yin, R. K. (2011). Applications of case study research. Sage.

Yin, R. K. (2014). Case Study Research: Design and Methods ( $5^{\text {th }}$ Ed.). Los Angeles: Sage Publications.

Young, K., Dick, M., Herring, K., \& Lee, J. (2008) From waiting lists to walk-in: Stories from a walk-in therapy clinic. Journal of Systemic Therapies 27(4): 23-39. 
